\title{
ER $\alpha$ and ER $\beta$ expression in correlation with Ki-67, Bcl-2 and Bak in primary tumors and lymph node metastases of breast cancer: The effect of pre-operative chemotherapy
}

\author{
LUIZA KANCZUGA-KODA ${ }^{1,2,3}$, MARIUSZ KODA ${ }^{1,2,3}$, JAKUB TOMASZEWSKI ${ }^{1,2,3}$, KATARZYNA JARZABEK ${ }^{4}$, \\ JOANNA LOTOWSKA ${ }^{1,2,3}$, MAREK BALTAZIAK ${ }^{1,2,3}$, URSZULA SULKOWSKA ${ }^{1,2,3}$, \\ MARIA SOBANIEC-LOTOWSKA ${ }^{1,2,3}$ and STANISŁAW SULKOWSKI ${ }^{1,2,3}$ \\ ${ }^{1}$ Department of Pathology, Maria Sklodowska-Curie Memorial Bialystok Oncology Center, 15-027 Bialystok;
${ }^{2}$ Jedrzej Sniadecki Memorial Hospital, 15-950 Bialystok; Departments of ${ }^{3}$ General Pathomorphology,
and ${ }^{4}$ Gynaecological Endocrinology, Medical University of Bialystok, 15-269 Bialystok, Poland
}

Received May 26, 2010; Accepted September 2, 2010

DOI: 10.3892/ol.2010.178

\begin{abstract}
This study aimed to assess the pre-operative chemotherapy impact on the relationship between estrogen receptor (ER) expression and markers of proliferation and apoptosis in primary and metastatic breast cancer. Immunohistochemical examinations were conducted on surgically removed ductal invasive breast cancers and their lymph node metastases in 135 patients. A total of 64 patients from this group underwent pre-operative chemotherapy and in 71 cases the surgery was performed without primary chemotherapy. A negative correlation between $\mathrm{ER} \alpha$ and $\mathrm{Ki}-67$ was found in primary tumors and lymph node metastases. A positive correlation was observed between ER $\alpha$ and Bcl-2. A positive correlation was also noted between ER $\beta$ and Bak, suggesting that the two ERs were involved in the regulation of proteins responsible for the control of the apoptotic process. Assessment of the expression of the proteins conducted separately in primary tumors and lymph node metastases did not reveal a significant effect of pre-operative chemotherapy on the correlations of ERs with Ki-67, Bcl-2 and Bak. However, the analysis of the correlations between the receptor expression in primary tumors and Ki-67, Bcl-2 and Bak in lymph node metastases showed a statistically significant impact of pre-operative chemotherapy on the correlations of $\mathrm{ER} \alpha$ and $\mathrm{Bcl}-2$ with $\mathrm{ER} \beta$ and Bak, confirming involvement of the two ERs in the regulation of apoptosis during breast carcinogenesis.
\end{abstract}

Correspondence to: Professor Stanislaw Sulkowski, Department of General Pathomorphology, Medical University of Bialystok, Waszyngtona 13, 15-269 Bialystok, Poland

E-mail: sulek@zeus.amb.edu.pl

Key words: breast cancer, primary tumor, lymph node metastasis, pre-operative chemotherapy, estrogen receptor, proliferation, apoptosis, $\mathrm{ER} \alpha, \mathrm{ER} \beta, \mathrm{Ki}-67, \mathrm{Bcl}-2$, Bak

\section{Introduction}

Estrogens play a key role in the development of breast cancer as they stimulate neoplastic cell proliferation. This proliferative effect occurs due to the induction of enzymes involved in nucleic acid synthesis, oncogene activation, as well as an increased production of various growth factors $(1,2)$. The effectiveness of hormonal therapies in breast cancer treatment depends mostly on the status of estrogen receptors (ERs). Typical hormonal therapies, including ER selective modulators, aromatase inhibitors and ovarectomy, inhibit estrogen activity. Hormonal therapy is used in different stages of cancer progression. However, only approximately $60 \%$ of breast cancers with a positive ER status respond to endocrine therapy (3). The molecular basis of this resistance remains unclear. A plausible reason is the disturbance of the ER $\alpha / E R \beta$ physiological relationship in primary breast cancer, or the dominant expression of one of the ER isoforms $(4,5)$. Numerous studies have suggested that ER $\alpha$-positive neoplasms develop mechanisms of growth and survival that are independent of ERs, such as through the overexpression of growth factors or their receptors, or changes in the proportions of proapoptotic and antiapoptotic proteins (6-12).

Breast cancer development and progression depends on the survival chances of genetically modified cells. The range of factors that stimulate and inhibit the processes of proliferation and apoptosis determine survival chances of neoplastic cells in primary tumor and metastatic foci $(13,14)$. However, despite intensive studies regarding ER expression and markers of proliferation and apoptosis in primary breast cancer, relatively little is known about the expression of these markers in metastatic foci, the main target of antineoplastic therapy. In previous studies, it was shown that pre-operative chemotherapy in breast cancer affects the expression of ERs and proteins involved in the processes of proliferation and apoptosis $(15,16)$. The present study aimed to assess the impact of pre-operative chemotherapy on the correlation of ER expression with Ki-67, Bcl-2 and Bak in the primary tumor of breast cancer and in axillary lymph node metastases. 
Table I. Correlation between estrogen receptors and Ki-67, Bcl-2 and Bak in primary tumors without pre-operative chemotherapy.

\begin{tabular}{|c|c|c|c|}
\hline \multicolumn{2}{|c|}{ Comparison of markers } & \multirow[t]{2}{*}{$\mathrm{p}$-value } & \multirow[t]{2}{*}{$\mathrm{r}$} \\
\hline PT $(n=71)$ & PT $(n=71)$ & & \\
\hline $\mathrm{ER} \alpha$ & Ki-67 & $<0.0001$ & -0.678 \\
\hline $\mathrm{ER} \alpha$ & Bcl-2 & $<0.0001$ & 0.572 \\
\hline $\mathrm{ER} \alpha$ & Bak & NS & -0.059 \\
\hline $\mathrm{ER} \beta$ & $\mathrm{Ki}-67$ & NS & 0.165 \\
\hline$E R \beta$ & $\mathrm{Bcl}-2$ & NS & -0.477 \\
\hline$E R \beta$ & Bak & $<0.0040$ & 0.350 \\
\hline
\end{tabular}

PT, primary tumors; NS, not significant; ER, estrogen receptor; $r$, correlation coefficient.

\section{Materials and methods}

Patients. This study comprised 135 female patients, aged 30-82 years (mean 54.4), treated surgically with partial or total mastectomy and lymph node dissection for primary breast cancer. Of this group, 64 patients underwent pre-operative chemotherapy and in 71 cases the surgery was performed without the preceding chemotherapy. In the group of cancers without pre-operative chemotherapy $(n=71)$, the presence of regional lymph node metastases was diagnosed in 35 cases. The analysis was performed only in cases of invasive ductal breast cancer in stages pT1 and pT2, as well as histological differentiation grades $\mathrm{G} 2$ and $\mathrm{G} 3$.

As previously described $(15,16)$, the proteins studied were not visualized due to substantial damage to primary tumor cells in 19 of the patients that underwent chemotherapy. Therefore, further analyses, including statistical evaluation, were performed in the group of 45 female patients with invasive ductal breast cancer, in which immunohistochemical evaluation of the markers examined was feasible despite preoperative chemotherapy. In this group of 45 female patients, the presence of regional lymph node metastases was diagnosed in 30 patients.

Methods. Tumor samples were fixed in $10 \%$ buffered formaldehyde solution, embedded in paraffin blocks at $56^{\circ} \mathrm{C}$ and routinely stained with hematoxylin and eosin. The histopathological examination was based on the World Health Organisation and pTN classifications of breast tumors. Tumor grade was assessed according to the Bloom-Richardson system. This study included only invasive ductal carcinomas, 63 in grade $\mathrm{G} 2$ and 46 in grade $\mathrm{G} 3$. The local ethics committee approved the protocol of the study. All the participants gave their informed consent prior to being included in the study.

Immunostaining was performed in two representative sections from the primary tumors and in 1-4 lymph nodes containing the largest metastatic breast carcinoma foci. $\mathrm{ER} \alpha, \mathrm{ER} \beta, \mathrm{Ki}-67, \mathrm{Bcl}-2$ and Bak expression was assessed as previously described (15-18).

An analysis was conducted of the correlations between the expression of particular protein pairs in the group of
Table II. Correlation between estrogen receptors and Ki-67, Bcl-2 and Bak in primary tumors with pre-operative chemotherapy.

\begin{tabular}{|c|c|c|c|}
\hline \multicolumn{2}{|c|}{ Compared markers } & \multirow[t]{2}{*}{$\mathrm{p}$-value } & \multirow[t]{2}{*}{$\mathrm{r}$} \\
\hline PT $(n=45)$ & $\mathrm{PT}(\mathrm{n}=45)$ & & \\
\hline $\mathrm{ER} \alpha$ & Ki-67 & $<0.0300$ & -0.342 \\
\hline $\mathrm{ER} \alpha$ & Bcl-2 & $<0.0040$ & 0.445 \\
\hline $\mathrm{ER} \alpha$ & Bak & NS & -0.071 \\
\hline$E R \beta$ & Ki-67 & NS & 0.054 \\
\hline ER $\beta$ & Bcl-2 & NS & -0.224 \\
\hline$E R \beta$ & Bak & $<0.0001$ & 0.586 \\
\hline
\end{tabular}

PT, primary tumors; NS, not significant; ER, estrogen receptor; $r$, correlation coefficient.

primary tumors and in that of axillary lymph node metastases, and between primary tumors and metastases. Subgroups of patients with and without pre-operative chemotherapy were distinguished.

Statistical analysis. Spearman's test was used to analyze the correlations between ER $\alpha, \mathrm{ER} \beta$ and $\mathrm{Ki}-67, \mathrm{Bcl}-2$ and Bak. $\mathrm{P}<0.05$ was considered to be statistically significant.

\section{Results}

In the groups evaluated for breast cancer, with and without pre-operative chemotherapy, no statistically significant relationship was observed between the expression of ER $\alpha, \operatorname{ER} \beta$, $\mathrm{Ki}-67, \mathrm{Bcl}-2$ and Bak and the age of patients. Considering the fact that previous studies $(15,16)$ thoroughly described morphological changes within the primary tumors treated with pre-operative chemotherapy, the correlations between protein expression and clinicopathological parameters were not analyzed in the present study.

Analysis of mutual relationship of the expression of ERa and ER $\beta$ with Ki-67, Bcl-2 and Bak in breast cancer without preoperative chemotherapy (in primary tumor and metastases). A negative correlation between the expression of ER $\alpha$ and Ki-67 was observed in the group of primary tumors (Table I), in metastases to lymph nodes (Table III), as well as between primary tumors and metastases to lymph nodes (Table V). In all of the above-mentioned groups, a positive correlation was observed between the expression of ER $\alpha$ and Bcl-2. None of these groups showed a correlation between ER $\alpha$ and Bak expression, ER $\beta$ and Ki-67 expression or Bcl-2 and Bak expression. However, a positive correlation was found between the expression of ER $\alpha$ and Bak in the group of primary tumors (Table I), as well as in metastases to lymph nodes (Table III).

Analysis of mutual relationship of ERo and ER $\beta$ with Ki-67, Bcl-2 and Bak in breast cancer following pre-operative chemotherapy (in primary tumor and metastases). As in the cases without pre-operative chemotherapy, a correlation between the analyzed markers was determined in primary tumors, lymph 
Table III. Correlation between estrogen receptors and Ki-67, Bcl-2 and Bak in lymph node metastases without pre-operative chemotherapy.

\begin{tabular}{|c|c|c|c|}
\hline \multicolumn{2}{|c|}{ Comparison of markers } & \multirow[t]{2}{*}{ p-value } & \multirow[t]{2}{*}{$\mathrm{r}$} \\
\hline $\operatorname{LNM}(n=35)$ & LNM (n=35) & & \\
\hline $\mathrm{ER} \alpha$ & $\mathrm{Ki}-67$ & $<0.0030$ & -0.501 \\
\hline $\mathrm{ER} \alpha$ & Bcl-2 & $<0.0001$ & 0.622 \\
\hline $\mathrm{ER} \alpha$ & Bak & NS & 0.003 \\
\hline $\mathrm{ER} \beta$ & $\mathrm{Ki}-67$ & NS & 0.127 \\
\hline $\mathrm{ER} \beta$ & Bcl-2 & NS & 0.039 \\
\hline $\mathrm{ER} \beta$ & Bak & $<0.0001$ & 0.706 \\
\hline
\end{tabular}

LNM, lymph node metastases; NS, not significant; ER, estrogen receptor; r, correlation coefficient.

Table IV. Correlation between estrogen receptors and Ki-67, Bcl-2 and Bak in lymph node metastases with pre-operative chemotherapy.

\begin{tabular}{|c|c|c|c|}
\hline \multicolumn{2}{|c|}{ Comparison of markers } & \multirow[t]{2}{*}{$\mathrm{p}$-value } & \multirow[t]{2}{*}{$\mathrm{r}$} \\
\hline LNM (n=30) & LNM $(\mathrm{n}=30)$ & & \\
\hline $\mathrm{ER} \alpha$ & Ki-67 & $<0.0300$ & -0.421 \\
\hline $\mathrm{ER} \alpha$ & $\mathrm{Bcl}-2$ & $<0.0030$ & 0.559 \\
\hline $\mathrm{ER} \alpha$ & Bak & NS & -0.062 \\
\hline $\mathrm{ER} \beta$ & Ki-67 & NS & 0.048 \\
\hline $\mathrm{ER} \beta$ & Bcl-2 & NS & -0.132 \\
\hline $\mathrm{ER} \beta$ & Bak & $<0.0001$ & 0.679 \\
\hline
\end{tabular}

LNM, lymph node metastases; NS, not significant; ER, estrogen receptor; r, correlation coefficient.

node metastases and between primary tumors and lymph node metastases.

As in the group without pre-operative chemotherapy, a negative correlation was observed between $\mathrm{ER} \alpha$ and $\mathrm{Ki}-67$, whereas a positive correlation was noted between $\mathrm{ER} \alpha$ and Bcl-2 in the group of primary tumors (Table II) and in lymph node metastases (Table IV). However, no such correlations were observed between primary tumors and lymph node metastases (Table VI). A trend was noted of a negative correlation of the expression of $\mathrm{ER} \alpha$ with $\mathrm{Ki}-67$ between primary tumor and lymph node metastases, and of a positive correlation between ER $\beta$ and Bak (Table VI).

\section{Discussion}

It is likely that genetic heterogeneity, which increases the ability of neoplastic cells to adapt to different environmental conditions, is fundamental for the development of breast cancer metastatic cell resistance to chemotherapeutics (19). For these reasons, determining the extent of differences between neoplastic cells present in primary tumor and metastatic foci
Table V. Correlation between estrogen receptors in primary tumors without pre-operative chemotherapy and Ki-67, Bcl-2 and Bak in lymph node metastases.

\begin{tabular}{lcccc}
\hline \multicolumn{2}{c}{ Comparison of markers } & & p-value & $r$ \\
\hline PT $(n=35)$ & LNM $(n=35)$ & & \\
\hline ER $\alpha$ & Ki-67 & $<0.0001$ & -0.619 \\
ER $\alpha$ & Bcl-2 & $<0.0020$ & 0.557 \\
ER $\alpha$ & Bak & NS & -0.211 \\
ER $\beta$ & Ki-67 & NS & 0.036 \\
ER $\beta$ & Bcl-2 & NS & -0.125 \\
ER $\beta$ & Bak & NS & 0.163
\end{tabular}

PT, primary tumors; LNM, lymph node metastases; NS, not significant; ER, estrogen receptor; $r$, correlation coefficient.

Table VI. Correlation between estrogen receptors in primary tumors with pre-operative chemotherapy and $\mathrm{Ki}-67, \mathrm{Bcl}-2$ and Bak in lymph node metastases.

\begin{tabular}{lcccc}
\hline \multicolumn{2}{c}{ Comparison of markers } & & p-value & $r$ \\
\hline PT $(n=30)$ & LNM (n=30) & & \\
\hline ER $\alpha$ & Ki-67 & 0.0890 & -0.333 \\
ER $\alpha$ & Bcl-2 & NS & 0.325 \\
ER $\alpha$ & Bak & NS & 0.063 \\
ER $\beta$ & Ki-67 & NS & 0.070 \\
ER $\beta$ & Bcl-2 & NS & -0.233 \\
ER $\beta$ & Bak & $<0.0200$ & 0.461 \\
\hline
\end{tabular}

PT, primary tumors; LNM, lymph node metastases; NS, not significant; ER, estrogen receptor; r, correlation coefficient.

appears to be a crucial issue in determining the biology of neoplasms, in clinical oncology, and in identifying novel methods of antineoplastic therapies. Concomitantly, previously published studies regarding the expression of ERs and markers of proliferation and apoptosis in breast cancer remain divergent, most probably due to the application of different methods and commercially available antibodies which detect different domains of ERs. Moreover, studies follow different procedures with regard to 'antigen exposing' and principles of incubation with antibodies, as well as in microscopic assessment criteria. Studies that analyzed the expression of ERs and other markers in breast cancer usually lacked information as to whether or not the cases analyzed included tumors without chemotherapy or tumors treated with pre-operative chemotherapy, and the extent thereof (20-24).

As with Rochaix et al (20), a positive correlation was observed in the present study between ER $\alpha$ expression and Bcl-2. Moreover, a positive correlation was noted between ER $\beta$ and Bak. This correlation suggests that the two ERs are involved in the regulation of proteins that control the apoptotic process. Rochaix et al (20) also found that the expression of 
ERs was considerably more frequent in Bcl-2-positive breast cancer as compared to Bcl-2-negative tumors. No relationship was observed between ER expression and Bak. Other studies have shown that estrogens increase $\mathrm{Bcl}-2$ protein expression in epithelial breast cells (21) and in certain breast cancer lines, thereby lengthening the life of these cells (22). Berardo et al (23) showed that a high Bcl-2 expression was associated with favorable prognostic factors, such as positive ER status, a low fraction of cells in the S-phase of the cell cycle and a low number of lymph nodes with neoplastic metastases. This expression was also to be correlated with longer survival. On the other hand, Sierra et al (24) observed a correlation between Bcl-2 overexpression and the presence of metastases, which was contradictory to the results of the present and other studies.

Previously, we showed that pre-operative chemotherapy affects breast cancer metastases to lymph nodes to a considerably lesser degree as compared to primary tumors. In the case of significant damage to the primary tumor, followed by an inability to determine ER expression, we demonstrated that tumor assessment may successfully be performed by means of metastases to local lymph nodes $(15,16)$. Although pre-operative chemotherapy did not significantly affect ER expression in the primary tumor, we observed its impact on the expression of proteins correlated with proliferation and apoptosis; therefore, it influences neoplastic process biology. The affect of neoadjuvant therapy on lymph node metastases, evaluated based on changes in the expression of the analyzed proteins, was relatively small, reducing the effectiveness of the therapy $(15,16)$. The results of the present study, in which the impact of pre-operative chemotherapy was taken into consideration, confirm our previous observations.

In histopathological diagnostics of breast cancer, the routine assessment of estrogen and progesterone receptors, as well as that of other proteins, is performed exclusively in primary tumor sections. It is assumed that the effects of chemotherapy or hormone therapy on breast cancer metastases to lymph nodes should be similar to the effects noted in the primary tumor. However, our observations, as well as other studies indicate that differences exist in the response to systemic therapy between the primary tumor and breast cancer metastases to lymph nodes. Heterogeneity in the expression of various biological factors between primary tumor cells and neoplastic cells in metastatic foci is a plausible reason for this discrepancy (19), as confirmed by the results of the present study.

Colonization of distant organs by neoplastic cells is the most hazardous feature of malignant neoplasms, while metastasis is the main cause of death of patients with malignant neoplasms. It is estimated that curability reaches $90 \%$ if breast cancer is diagnosed in the gland only, whereas in the case of neoplastic cell dissemination long-term survival decreases depending on the tissues and organs involved (25). At present, our knowledge regarding genetic changes associated with neoplastic dissemination is relatively poor. Moreover, few studies are currently available on biological markers in metastatic foci, particularly with regard to primary tumors. Further attempts to determine whether the assessment of markers in metastases is of a prognostic value are required.

We believe that studies that compare changes in metastatic and primary foci may provide information regarding differ- ences between the primary tumor and its foci, indicating that certain factors are pre-disposed to neoplasm dissemination. Moreover, research on cancers treated with chemotherapy may help to explain the mechanisms whereby metastatic cells develop resistance to chemotherapeutics, which may be useful in determining the most effective therapeutic methods and creating possibilities for individualized treatment.

\section{References}

1. Stewart AJ, Westley BR and May FE: Modulation of the proliferative response of breast cancer cells to growth factors by oestrogen. Br J Cancer 66: 640-648, 1992.

2. Santen RJ, Fan P, Zhang Z, Bao Y, Song RX and Yue W: Estrogen signals via an extra-nuclear pathway involving IGF-1R and EGFR in tamoxifen-sensitive and -resistant breast cancer cells. Steroids 74: 586-594, 2009.

3. Yamashita $\mathrm{H}$ : Current research topics in endocrine therapy for breast cancer. Int J Clin Oncol 13: 380-383, 2008.

4. Hopp TA, Weiss HL, Parra IS, Cui Y, Osborne CK and Fuqua SA: Low levels of estrogen receptor beta protein predict resistance to tamoxifen therapy in breast cancer. Clin Cancer Res 10: 7490-7499, 2004.

5. Gonzalez-Angulo AM, Morales-Vasquez F and Hortobagyi GN: Overview of resistance to systemic therapy in patients with breast cancer. Adv Exp Med Biol 608: 1-22, 2007.

6. Bos R, van Diest PJ, van der Groep P, Shvarts A, Greijer AE and van der Wall E: Expression of hypoxia-inducible factor-1alpha and cell cycle proteins in invasive breast cancer are estrogen receptor related. Breast Cancer Res 6: R450-R459, 2004.

7. Nolan MK, Jankowska L, Prisco M, Xu S, Guvakova MA and Surmacz E: Differential roles of IRS-1 and SHC signaling pathways in breast cancer cells. Int J Cancer 72: 828-834, 1997.

8. Surmacz E: Function of the IGF-I receptor in breast cancer. J Mammary Gland Biol Neoplasia 5: 95-105, 2000.

9. Koda M, Sulkowski S, Kanczuga-Koda L, Surmacz E and Sulkowska M: Expression of ER $\alpha$, ER $\beta$ and Ki-67 in primary tumors and lymph node metastases in breast cancer. Oncol Rep 11: 753-759, 2004.

10. Koda M, Sulkowska M, Kanczuga-Koda L and Sulkowski S: Expression of insulin receptor substrate 1 in primary breast cancer and lymph node metastases. J Clin Pathol 58: 645-649, 2005.

11. Koda M, Kanczuga-Koda L, Reszec J, Sulkowska M, Famulski W, Baltaziak M, Kisielewski W and Sulkowski S: Expression of the apoptotic markers in normal breast epithelium, benign mammary dysplasia and in breast cancer. Folia Morphol 63: 337-341, 2004.

12. Garofalo C, Koda M, Cascio S, Sulkowska M, Kanczuga-Koda L, Golaszewska J, Russo A, Sulkowski S and Surmacz E: Increased expression of leptin and the leptin receptor as a marker of breast cancer progression: possible role of obesity-related stimuli. Clin Cancer Res 12: 1447-1453, 2006.

13. Redondo M, Garcia J, Rodrigo I, Villar E, González C and Morell M: Expression of bax and p53 proteins in the tumorigenesis and progression of breast carcinomas. Tumor Biol 24: 23-31, 2003.

14. Arun B, Kilic G, Yen C, Foster B, Yardley D, Gaynor R and Ashfaq R: Correlation of $\mathrm{Bcl}-2$ and $\mathrm{p} 53$ expression in primary breast tumors and corresponding metastatic lymph nodes. Cancer 98: 2554-2559, 2003.

15. Koda M, Lenczewski A, Sulkowska M, Kanczuga-Koda L, Wincewicz A, Tomaszewski J and Sulkowski S: The effect of chemotherapy on status of estrogen receptors in primary tumors and lymph node metastases of human ductal breast cancer. Oncol Rep 17: 385-391, 2007.

16. Koda M, Sulkowska M, Kanczuga-Koda L, Tomaszewski J, Kucharczuk W, Lesniewicz T, Cymek S and Sulkowski S: The effect of chemotherapy on Ki-67, Bcl-2 and Bak expression in primary tumors and lymph node metastases of breast cancer. Oncol Rep 18: 113-119, 2007.

17. Koda M, Sulkowski S, Garofalo C, Kańczuga-Koda L, Sulkowska $M$ and Surmacz E: Expression of the insulin-like growth factor-I receptor in primary breast cancer and lymph node metastases: correlations with estrogen receptors $\alpha$ and $\beta$. Horm Metab Res 35: 794-801, 2003. 
18. Koda M, Przystupa W, Jarzabek K, Wincewicz A Kanczuga-Koda L, Tomaszewski J, Sulkowska M, Wolczynski S and Sulkowski S: Expression of insulin-like growth factor-I receptor, estrogen receptor $\alpha, \mathrm{Bcl}-2$ and Bax proteins in human breast cancer. Oncol Rep 14: 93-98, 2005.

19. Wu JM, Fackler MJ, Halushka MK, Molavi DW, Taylor ME, Teo WW, Griffin C, Fetting J, Davidson NE, De Marzo AM, Hicks JL, Chitale D, Ladanyi M, Sukumar S and Argani P: Heterogeneity of breast cancer metastases: comparison of therapeutic target expression and promoter methylation between primary tumors and their multifocal metastases. Clin Cancer Res 14: 1938-1946, 2008.

20. Rochaix P, Krajewski S, Reed JC, Bonnet F, Voigt JJ and Brousset $\mathrm{P}$ : In vivo patterns of $\mathrm{Bcl}-2$ family protein expression in breast carcinomas in relation to apoptosis. J Pathol 187: 410-415, 1999.

21. Ferrieres G, Cuny M, Simony-Lafontaine J, Jacquemier J, Rouleau C, Guilleux F, Grenier J, Rouanet P, Pujol H, Jeanteur P and Escot C: Variation of bcl-2 expression in breast ducts and lobules in relation to plasma progesterone levels: overexpression and absence of variation in fibroadenomas. J Pathol 183: 204-211, 1997.
22. Leung LK and Wang TT: Paradoxical regulation of Bcl-2 family proteins by $17 \beta$-oestradiol in human breast cancer cells MCF-7. Br J Cancer 81: 387-392, 1999.

23. Berardo MD, Elledge RM, de Moor C, Clark GM, Osborne CK and Allred DC: Bcl-2 and apoptosis in lymph node positive breast carcinoma. Cancer 82: 1296-1302, 1998.

24. Sierra A, Castellsague X, Coll T, Manas S, Escobedo A, Moreno A and Fabra A: Expression of death-related genes and their relationship to loss of apoptosis in $\mathrm{T} 1$ ductal breast carcinomas. Int J Cancer 79: 103-110, 1998.

25. Gueth U, Huang DJ, Schoetzau A, Holzgreve W and Wight E: Systemic therapy of metastatic breast cancer: the truth beyond the clinical trials. Oncology 76: 247-253, 2009. 